\title{
Field Evaluation of a New Sequential Sampling Technique for Determining Apple Scab "Risk"
}

\author{
J. E. Reardon, L. P. Berkett, M. E. Garcia, and A. Gotlieb, Department of Plant and Soil Science, and
} T. Ashikaga and G. Badger, Medical Biostatistics, University of Vermont, Burlington 05405

\begin{abstract}
Reardon, J. E., Berkett, L. P., Garcia, M. E., Gotlieb, A., Ashikaga, T., and Badger, G. 2005. Field evaluation of a new sequential sampling technique for determining apple scab "risk". Plant Dis. 89:228-236.

Most fungicide sprays applied to apple orchards in the New England states are targeted at the management of apple scab. Researchers have developed action thresholds that aid in decisionmaking on whether early spring fungicide applications could be eliminated without a significant increase in the incidence of fruit scab at harvest. To facilitate grower adoption of these thresholds, a simplified, sequential sampling technique in autumn to determine the "scab risk" of an orchard for the following spring was proposed in the scientific literature. However, this technique had not been evaluated in the field. In autumn 1999, 2000, and 2001, orchards were evaluated using the new sequential sampling technique to determine scab risk. Risk ratings were compared with those obtained by the original, nonsequential procedure in each orchard. Data also were examined using a simulation sequential sampling computer program to determine whether or not risk ratings would change if different trees or shoots were used. In two of the assessed orchards, "delayed-spray" experiments involving two treatments (a delayed-spray and full-spray treatment) were conducted in 2000 and 2001. Delayed-spray replicates were to receive no fungicide sprays until after the third primary infection period (but before the fourth) or until the pink stage of bud development, whichever came first; full-spray replicates received fungicide sprays starting at the green-tip stage of bud development. The sequential sampling technique provided scab-risk ratings consistent with the original, nonsequential procedure, at potentially significant time savings. Also, following the delayed-spray strategy in low-risk orchards did not result in significant differences in fruit scab at harvest compared with initiating spraying at the green-tip phenological bud stage.
\end{abstract}

Additional keywords: PAD, potential ascospore dose, Venturia inaequalis

Apple scab, caused by the fungus Venturia inaequalis (Cooke) G. Wint., is one of the greatest disease threats to the New England apple industry, and most fungicide treatments are directed at its management (3). Fungicide applications can begin shortly after bud break in the spring and continue through late summer, for a total of approximately 12 fungicide applications in a protective spray program.

$V$. inaequalis overwinters primarily as pseudothecia in infected apple leaves that have fallen to the orchard floor (12), and the ascospores that are discharged from pseudothecia are the most important source of primary inoculum in North America (12). The part of the growing season when ascospores are being discharged is a key period in fungicide-based disease management $(1,8)$.

Corresponding author: L. P. Berkett

E-mail: Lorraine.Berkett@uvm.edu

Accepted for publication 8 August 2004.

DOI: 10.1094/PD-89-0228

(C) 2005 The American Phytopathological Society
Researchers have developed ways to effectively target the use of fungicides and eliminate unnecessary applications during the primary stage of disease development (i.e., the ascosporic stage) by integrating models or techniques to estimate (i) the potential ascospore dose (PAD) of an orchard in the autumn $(2,7,11,13,16,17)$, (ii) ascospore maturity in the spring (6), and (iii) ascosporic infection periods (i.e., primary infection periods) $(15,20)$. Action thresholds have been developed to aid in decision-making on whether early spring fungicide applications could be eliminated without a significant increase in the incidence of fruit scab at harvest (i.e., the "delayed-spray" strategy) $(2,11,13,16)$.

The PAD is calculated by using an equation involving factors such as lesion density, pseudothecial density, ascal density, leaf litter density, and the number of ascospores per ascus, and expressed as the number of ascospores per square meter of orchard floor (7). Development of a nonsequential sampling procedure that related the number of scabbed leaves on 600 extension shoots (10 shoots by 60 trees) to the PAD (13) allowed the PAD concept to be applied more easily by growers who wanted to assess the "scab risk" of their orchards in the autumn to determine whether the orchards were candidates for the delayed-spray strategy the following spring (10). An orchard with a low level of foliar scab in the autumn would be at "low risk" of early-season scab infections the following spring and, thus, fungicide applications could be delayed until after three primary infection periods or until the pink phenological stage of bud development, whichever came first (i.e., the action threshold) $(2,11,13,16)$. Orchards with intermediate or high levels of foliar scab would be designated "high risk" and would not be candidates for the delayed-spray strategy. Implementation of the delayedspray strategy in appropriate orchards would reduce the total fungicide dose applied per orchard and allow for better integration of fungicide and insecticide application at the pink bud stage. Spray integration has many advantages to the grower, including reduced cost of labor, equipment, and materials, and reduced early-season travel through the orchard in wet spring conditions (8). Reduction in applications of some fungicides also may translate into reduced pressure for the development of fungicide resistance. However, the time required to evaluate 60 trees per orchard in the original, nonsequential sampling procedure limited its adoption by growers.

To facilitate grower adoption, a simplified, sequential sampling technique, based on the statistical analysis of 66 historical autumn assessments of foliar scab in predominantly 'McIntosh' commercial orchards in New England over several years, was proposed (14). The new sampling technique potentially would reduce the time required in the autumn to assess the level of foliar scab and determine scab risk. The proposed sequential sampling technique predicted with $95 \%$ confidence whether the orchard was at low or high risk of developing unacceptable levels of fruit scab the following year if the delayedspray strategy were to be implemented (14) and was included in the New England Apple Pest Management Guide for growers to use (1).

However, the proposed sequential sampling technique had not yet been evaluated in the field. The major objectives of this research were to (i) determine whether the outcome of the sequential sampling technique consistently agreed with the outcome of the original sampling procedure 
(nonsequential) to estimate the scab risk of an orchard, (ii) determine how consistent the sequential sampling technique was in identifying whether an orchard was a lowor high-risk orchard when different trees and shoots were chosen for sampling, and (iii) determine whether using the delayedspray strategy in orchards identified as low risk by the sequential sampling technique would result in commercially unacceptable levels of scabbed fruit at harvest (i.e., $>1 \%$ ).

\section{MATERIALS AND METHODS}

Sequential sampling experiments, 1999, 2000, and 2001. Three orchards were assessed in the autumn of 1999 to determine scab risk using the sequential sampling technique proposed by MacHardy et al. (14). Orchards were selected based on the expectation, given the management practices used during the growing season, that they would have low to intermediate levels of foliar scab (i.e., represent low-risk to high-risk orchards). Two of the orchards were at the University of Vermont (UVM) Horticultural Research Center (UVM orchards 9 and 11) and the other was a commercial orchard in New Haven, VT (orchard A-1) (Table 1). Sampling protocol required examining 10 vegetative extension shoots on a minimum of 10 trees selected from the entire orchard (e.g., if there were 1,000 trees in the orchard, approximately every 100th tree was assessed). Shoots were selected from high, low, exterior, and interior parts of the canopy on each tree. On each extension shoot, the upper and lower surfaces of each leaf were examined and the number of scabbed leaves recorded. After assessing 10 trees, the number of scabbed leaves was totaled. The time required to assess the 10 trees also was recorded. Once the initial 10 trees were sampled, five additional sets of 10 trees were sampled, regardless of whether the number of scabbed leaves indicated further sampling was needed according to the sequential sampling chart (Fig. 1). Each set of 10 trees (six sets to complete a total of 60 trees) was sampled independently; each set was sampled from the entire orchard and trees were marked with tape to ensure that no tree was sampled twice. Thus, 60 trees, 10 extension shoots per tree, were assessed as was called for in the original (nonsequential) procedure developed by MacHardy (13).

In autumn 2000 and 2001, these three orchards and additional commercial orchards (Table 1) were assessed to determine their scab risk level using the sequential sampling technique that was used in 1999 , except that 20 shoots instead of 10 extension shoots were sampled from each tree and, because additional shoots were sampled, the time required to complete the sampling was not noted. Sampling of additional extension shoots per tree allowed for statistical determination of whether the same result (low or high risk) would be attained in an orchard regardless of the

Table 1. Description of Vermont orchards and year of autumn scab-risk assessment

\begin{tabular}{|c|c|c|c|c|c|}
\hline Orchard designation $^{\mathrm{a}}$ & Year assessed $^{b}$ & Location & Cultivar & Rootstock $^{\mathrm{c}}$ & Year planted \\
\hline A-1 & 1999 & New Haven & Rogers McIntosh & M.7 & 1983 \\
\hline A-2 & 2000 & New Haven & Rogers McIntosh & M.7 & 1983 \\
\hline A-3 & 2000 & New Haven & Rogers McIntosh & M.7 & 1983 \\
\hline A-4 & 2000 & New Haven & Rogers McIntosh & M.7 & 1983 \\
\hline B & 2000,2001 & Shoreham & McIntosh & M.9 & 1995 \\
\hline $\mathrm{C}$ & 2000 & Shoreham & McIntosh & M.26 and interstem M.9/MM.106 & 1983 \\
\hline D-1 & 2000 & Saxtons River & Empire & MM.106 & 1982 \\
\hline D-2 & 2000 & Saxtons River & McIntosh & MM.106 & 1980 \\
\hline E-1 & 2001 & Shoreham & McIntosh & MM.106 & 1970 \\
\hline E-2 & 2001 & Shoreham & Empire & MM.106 & 1980 \\
\hline $\mathrm{F}$ & 2001 & Shoreham & McIntosh & M.26 & 1992 \\
\hline UVM orchard 9 & 1999, 2000, 2001 & South Burlington & RedMax McIntosh & M.26 & 1988 \\
\hline UVM orchard 11 & 1999, 2000, 2001 & South Burlington & Empire & MARK and M.7 & 1990 \\
\hline
\end{tabular}

a UVM = University of Vermont.

${ }^{b}$ All leaves on 10 vegetative extension shoots per tree in 1999 and on 20 vegetative extension shoots per tree in 2000 and 2001 were examined for the presence of scab lesions. A total of 60 trees per orchard (i.e., six sets of 10 trees) were assessed in late September or early October of each year.

${ }^{c}$ All trees sampled were of a size appropriate for the sequential sampling procedure (approximately 3 to $4 \mathrm{~m}$ tall).

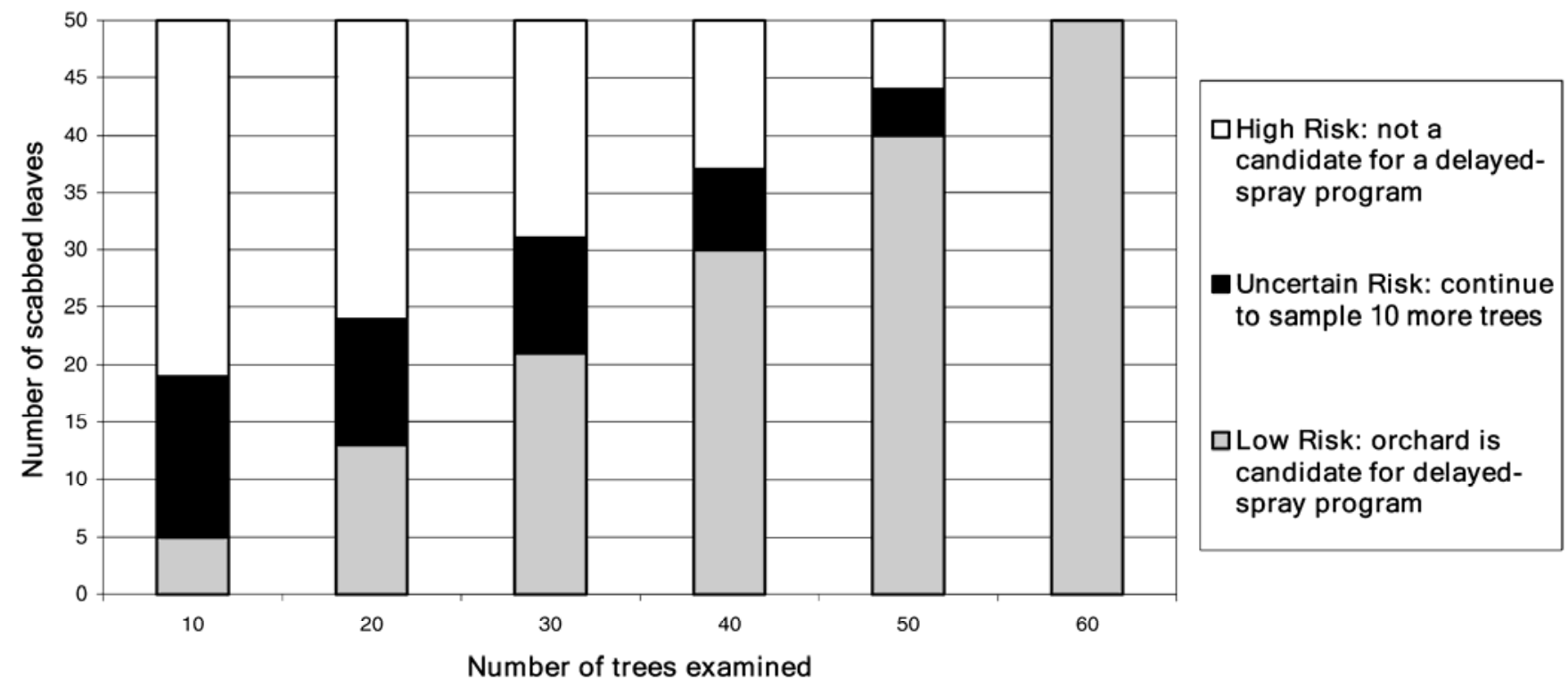

Fig. 1. Sequential sampling chart describing scab-risk thresholds based on the number of scabbed leaves for each set of 10 trees sampled. Proposed by MacHardy et al. (1999) and MacHardy (personal communication). 
number of extension shoots chosen for assessment. The additional commercial orchards represented historically wellmanaged orchards (i.e., orchards that would be likely to have low to intermediate levels of foliar scab).

Delayed-spray experiments, 2000 and 2001. Research was conducted in UVM orchards 9 and 11. Orchard 9 contained the cv. RedMax McIntosh (a common strain of 'McIntosh') on Malling 26 (M.26). The trees in orchard 11 consisted of the cv. Empire planted on MARK and Malling 7 (M.7) rootstocks (Table 1). Sterol biosynthesis-inhibiting (SBI) fungicides (i.e., myclobutanil, triflumizole, or fenarimol), which can inhibit scab lesion formation, were not used in either orchard during the previous growing season.

A completely randomized design was used in each orchard to evaluate two treatments (a delayed-spray and full-spray treatment) in two growing seasons (2000 and 2001). In both growing seasons, delayed-spray replicates were to receive no fungicide sprays until after the third primary infection period (but before the fourth) or until the pink stage of bud development, whichever came first, which was the recommended action threshold (Table 2) (1,13). However, in 2001, there were no infection periods until the bloom stage and, thus, the first fungicide was applied during bloom after the infection period (Table 2). Full-spray replicates received fungicide sprays starting at the green-tip stage of bud development, as recom- mended in the New England Apple Pest Management Guide (1). Treatment replicates involved the same trees in both 2000 and 2001 in order to more closely represent a commercial orchard situation where the same trees might be involved in a delayed-spray program over multiple years.

The experiment in UVM orchard 9 involved 12 delayed-spray replicates and 11 full-spray replicates; in UVM orchard 11, each treatment had 11 replicates. In both orchards, each replicate consisted of a twotree plot. The 'Empire' trees in orchard 11 occurred on both MARK and M.7 rootstocks; therefore, treatments were divided as equally as possible between each rootstock. In addition, a small section of orchard 11 was set aside to receive no fungicide treatment for the entire growing season of both years. These trees served as a check for determining the potential level of scab development.

Fungicides, dates of application, rates, and equipment are listed in Table 2. At the beginning of the growing season, tree measurements were taken in each orchard to calculate the tree row volume (TRV), which determined the amount of spray volume needed to fully cover the experimental trees (10). Fungicides applied to full-spray replicates, prior to when the delayed-spray applications commenced, were applied with a handgun. Afterward, when both the full-spray and delayedspray replicates were receiving fungicides, an airblast sprayer was used to spray all trees in the orchards. To protect against drift between full-spray and delayed-spray replicates in orchard 11 before treatment was initiated on the latter, tarps were placed strategically downwind from full-spray replicates. Tarps were not deemed necessary in UVM orchard 9 because replicates were protected by a buffer row of nonexperimental trees. Water-sensitive paper was placed in select delayed-spray replicates in both orchards to verify that no spray had drifted from full-spray replicates early in the season. All trees in both orchards received insecticide, miticide, and horticultural sprays and standard cultural practices based on Extension recommendations (10).

A rain gauge and leaf wetness and temperature sensors (Davis Weather System, product \#7450/7455) connected to a computer with Grow Weather software (Davis Instruments, Hayward, CA) recorded environmental conditions at the UVM orchards. Data were used to determine primary infection periods (Table 2). Infection periods were calculated using the "revised" Mills table developed by MacHardy and Gadoury (15) and further modified by Stensvand et al. (20), with the exception that wetting periods initiated by nighttime rains were included in the calculations because a portion of ascospores are released at night (9). Ascospore maturity was calculated using the New Hampshire model developed by Gadoury and MacHardy (6). The potential release of mature ascospores during rain events was determined according to criteria established by Gadoury et al. (9).

Table 2. Fungicide applications in relation to primary infection periods, ascospore maturity, and release in University of Vermont orchards 9 and 11

\begin{tabular}{|c|c|c|c|c|c|}
\hline Year, date of sprays & Phenology ${ }^{\mathbf{a}}$ & Fungicide applied & $\begin{array}{l}\text { Date of primary } \\
\text { infection periods }\end{array}$ & Ascospore maturity $(\%)^{\mathrm{e}}$ & $\begin{array}{c}\text { Total seasonal ascospores } \\
\text { released }(\%)^{\mathbf{f}}\end{array}$ \\
\hline \multicolumn{6}{|l|}{2000} \\
\hline 17 April & HIG, HIG & Mancozeb $^{b}$ & 21-24 April & $6-7$ & 5.6 \\
\hline 26 April & HIG & Mancozeb $^{b}$ & $\ldots$ & $\ldots$ & $\ldots$ \\
\hline 03 May & $\mathrm{TC}$ & Mancozeb $^{b}$ & $\ldots$ & $\ldots$ & $\ldots$ \\
\hline$\ldots$ & B & $\ldots$ & 8-12 May & $52-70$ & 29.1 \\
\hline 11 May & $\mathrm{B}, \mathrm{B}$ & Kresoxim-methyl $^{\mathrm{c}}$ & 13-14 May & $75-79$ & 11.0 \\
\hline 17 May & Early PF, PF & Mancozeb $^{c}$ & 18-19 May & $89-90$ & 11.2 \\
\hline 22 May & $\mathrm{PF}, \mathrm{PF}$ & Captan ${ }^{\mathrm{c}}$ & 23-25 May & $96-98$ & 7.6 \\
\hline 01 June & $\ldots$ & Captan ${ }^{\mathrm{c}}$ & $\ldots$ & $\ldots$ & $\ldots$ \\
\hline \multicolumn{6}{|l|}{2001} \\
\hline 23 April & GT & Mancozeb $^{b}$ & $\ldots$ & $\ldots$ & $\ldots$ \\
\hline 29 April & HIG & Mancozeb $^{b}$ & $\ldots$ & $\ldots$ & $\ldots$ \\
\hline 09 May & $\mathrm{B}, \mathrm{B}$ & Mancozeb $^{b}$ & 12-13 May & $58-61$ & 49.4 \\
\hline 14 May & $\mathrm{B}, \mathrm{B}$ & Captan ${ }^{\mathrm{c}}$ & 19 May & 83 & 13.4 \\
\hline 21 May & Early PF, PF & Captan ${ }^{\mathrm{c}}$ & 23-24 May & $94-95$ & 22.8 \\
\hline 24 May & $\mathrm{PF}, \ldots$ & Captan ${ }^{\mathrm{c}}$ & 26-29 May & $98-99$ & 5.3 \\
\hline 01 June & $\ldots$ & Kresoxim-methyl $^{\mathrm{c}}$ & $\ldots$ & $\ldots$ & $\ldots$ \\
\hline
\end{tabular}

a Phenology on date of sprays, date of infection periods determined by criteria in Chapman and Catlin $(5)$. GT $=$ green tip, HIG $=$ half-inch green, TC $=$ tight cluster, $\mathrm{P}=$ pink, $\mathrm{B}=$ bloom, and $\mathrm{PF}=$ petal fall

${ }^{\mathrm{b}}$ Only the full-spray replicates were sprayed with mancozeb (Manzate $200 \mathrm{DF}$; E. I. DuPont de Nemours Co., Wilmington, DE) applied at 1.8 g/liter (2000) or 2.4 g/liter (2001) with a handgun (Green Guard model JD9-C with an L tip) connected to a 379-liter 3-point hitch PTO sprayer (Pak Tank) at 827.4 kPa with the exception of the 17 April 2000 spray, which was applied at a pressure of $413.7 \mathrm{kPa}$.

c Both delayed- and full-spray replicates received, as indicated, kresoxim -methyl (Sovran; BASF, Research Triangle Park, NC) applied at 0.125 ml/liter, mancozeb (Manzate $200 \mathrm{DF}$ ) at $1.8 \mathrm{~g} / \mathrm{liter}$, and captan (Captec 4L; Micro Flo Co. LLP, Memphis, TN) at $2.5 \mathrm{ml} / \mathrm{liter}$ with an airblast sprayer (Rears Mfg. Co., Eugene, OR) at 2,068.4 kPA. All trees received five to six additional fungicide applications during the remainder of the growing season.

d Primary infection periods were calculated using the revised Mills table developed by MacHardy and Gadoury (15) and further modified by Stensvand et al. (20), with the exception that wetting periods initiated by nighttime rains were included in the calculations because a portion of ascospores are released at night (9).

e Estimated ascospore maturity at each infection period as determined by Gadoury and MacHardy (6) model.

f Potential ascospore discharge during infection period calculated according to criteria developed by Gadoury et al. (9). 
Orchards were monitored biweekly in the spring to record the date of each stage of fruit bud development. Stages of fruit bud development were determined by standard criteria (5).

In June of each year, scab incidence was assessed on the foliage of fruit clusters and extension shoots in both orchards. Both sides of all leaves on 10 fruit clusters and 10 extension shoots per tree per replicate, selected within arm's reach around the tree, were examined for the presence of scab lesions. Total number of scabbed leaves per cluster and per shoot was noted along with the total number of leaves present. In August 2001, a second foliar evaluation was conducted on 10 extension shoots per tree per replicate in both orchards.

In addition, foliar scab incidence on fruit clusters and extension shoots was assessed on six 'Empire' trees in the nonfungicide-treated section of UVM orchard 11 and on 10 'McIntosh' trees in another nonfungicide-treated UVM orchard (UVM orchard 10) in both years (18). These data served as an informal comparison of the level of scab found in the treated section of orchards 11 and 9, respectively.

In August, 50 fruit from each tree in the two-tree plots in UVM orchards 9 and 11 (100 apples per replicate) were harvested and examined for scab lesions. The fruit were selected from all parts of the tree canopy (i.e., the upper, middle, and lower canopy, and from the inside as well as the periphery of the canopy). Fruit either were boxed and refrigerated at approximately $2^{\circ} \mathrm{C}$ until examined, or examined as they were harvested from the tree. Twenty fruit also were evaluated at harvest on each of the nonsprayed trees in orchards 10 and 11 on which foliar observations were made.

In autumn 2000, sanitation measures were undertaken to minimize movement of fallen scabbed leaves from the nonsprayed section of UVM orchard 11 into the section designated as low risk. On 15 to 16 November, when the trees were approximately $90 \%$ defoliated, the fallen leaves were raked into the row middles of the nonsprayed section of the orchard. On 17 November, a solution of $59.9 \mathrm{~g}$ of urea per liter of water was sprayed until the top surface of the fallen leaves was very wet. The leaves then were mowed with a chainflail mower set to mow down to soil level. After the mowing was completed, the rows were sprayed again with the urea solution. It has been determined that application of urea to fallen leaves hinders pseudothecial development and enhances decomposition of the leaf litter $(4,19)$. A study by Sutton et al. (21) showed that shredding all of the leaf litter in November reduced the risk of scab by 80 to $90 \%$, or by 50 to $65 \%$ if only 65 to $90 \%$ of the leaf litter could be shredded. That study also found that application of urea to leaf litter in November could reduce numbers of ascospores trapped in the orchard in the spring by $50 \%$.
Statistical analysis. Autumn scab-risk assessment data collected in 2000 and 2001 in the sequential sampling experiments were analyzed with a simulation program (18) developed to run in SAS (SAS Institute Inc., Cary, NC). The program randomly selected a tree on which to begin the assessment from all of the 60 possible trees in the data set, then randomly selected 10 extension shoots from the total of 20 extension shoots on that tree. The program continued to randomly select trees and extension shoots until a total of 10 trees had been selected. Once a tree was selected by the program, it was taken out of the selection pool so that it could not be selected twice. The program then determined whether the first 10 trees indicated a low- or high-risk rating, or whether sampling had to continue, according to the sequential sampling technique thresholds (Fig. 1). If it was determined that sampling had to continue because the number of scabbed leaves was intermediate (i.e., above the threshold for a low-risk rating but below the threshold for a highrisk rating), the process of selecting 10 random trees and 10 extension shoots from the remaining trees was repeated until a maximum of 60 trees had been sampled. This entire process was repeated 100 times per orchard, generating data on how many times an orchard was determined to be at low or high risk.

In the delayed-spray experiments, the foliar and fruit scab incidence data were transformed with an arcsine square root transformation to account for the population variance of proportional data. A twosample $t$ test was used to test equality of means. Alpha was held at 0.05 for all tests,

Table 3. Autumn scab-risk assessments for University of Vermont orchards 9 and 11 and commercial orchard A-1, 1999a

\begin{tabular}{lccccccc}
\hline & \multicolumn{5}{c}{ No. of scabbed leaves found on each set of 10 trees } & \\
\cline { 2 - 7 } Orchard & First set & Second set & Third set & Fourth set & Fifth set & Sixth set & Total \\
\hline 9 & 3 & 3 & 2 & 3 & 2 & 2 & 15 \\
11 & 0 & 0 & 0 & 0 & 0 & 0 & 2 \\
A-1 & 2 & 2 & 9 & 4 & 6 & 7 & 30 \\
\hline
\end{tabular}

a All leaves on 10 extension shoots per tree were evaluated for presence of scab lesions. Based on the sequential sampling technique proposed by MacHardy et al. (14), as few as one set of 10 trees can determine the scab risk of an orchard. For the first 10 trees sampled to indicate a low-risk orchard, the total number of scabbed leaves must be $<5$. If the number of scabbed leaves was $\geq 5$ but $\leq 19$, sampling of an additional 10 trees would be required. If the number of scabbed leaves was $>19$, the orchard would be declared high risk and sampling would be discontinued. The low and high thresholds for the second, third, fourth, and fifth additional set of 10 trees sampled are 13 and 24, 21 and 31,30 and 37, and 40 and 44, respectively. If all 60 trees are sampled, a total of $\leq 50$ scabbed leaves indicates a low-risk orchard for apple scab. Total $=$ total number of scabbed leaves on 60 trees.

Table 4. Average time to complete the autumn assessments of scab risk, 1999

\begin{tabular}{lccc}
\hline & \multicolumn{3}{c}{ Length of time (min) } \\
\cline { 2 - 4 } Orchard & $\begin{array}{c}\text { Sequential sampling } \\
\text { of 10 trees }\end{array}$ & $\begin{array}{c}\text { Total time to sample } \\
\text { 60 trees }\end{array}$ & Difference \\
\hline University of Vermont orchard 9 & 39 & 248 & 209 \\
University of Vermont orchard 11 & 35 & 275 & 240 \\
Commercial orchard A-1 & 35 & 240 & 205 \\
\hline
\end{tabular}

and $t$ tests were performed with SAS soft-

RESULTS

1999 , all orchards were below the threshold of five scabbed leaves on the first 10 considered at low risk for apple scab the next season based upon the sequential five additional sets of 10 trees in the UVM orchards produced the same risk level; the low-risk threshold for each set of trees. been the initial sampling set, the sequential pling technique would have required ber of scabbed leaves from that particular between the range high-risk ratings. Nevertheless, the total was below the threshold (i.e., 50 scabbed , as it was in the UVM orchards, risk. The average time saved by using the (nonsequential) procedure is shown in Table 4. The sequential sampling techpled, required an average of $36 \mathrm{~min}$, which of $254 \mathrm{~min}(4.23 \mathrm{~h})$ needed to complete the sampled.

A total of 20 extension shoots were examined per tree in 2000 and 2001, and the wever, in commercial orchard A-1, if minential sampling technique to deterwas $218 \mathrm{~min}(3.63 \mathrm{~h})$ less than the average

a Average of six sets of 10 trees.

the orchard in the spring by $50 \%$. 
sequential sampling protocol and the original, nonsequential procedure required only 10 shoots per tree; therefore, the data for each orchard were divided arbitrarily into two groups: one group contained data from 10 extension shoots per tree (i.e., every other shoot examined) and the other group contained the remaining observations (Tables 5 and 6). When each of the six sets of 10 trees (i.e., sample sets 1 to 6) was evaluated as if each were the initial sample set in the sequential sampling technique and the number of scabbed leaves on each set of trees for each data group of shoots was compared with the thresholds illustrated in Figure 1, there were 20 of 180 assessments (i.e., six sets of 10 trees $\times$ two data groups $\times 15$ orchards evaluated in 2000 and 2001) where sampling a single set of 10 trees did not result in a low-risk or high-risk rating. In these 20 assess-

Table 5. Autumn scab-risk assessments, 2000

\begin{tabular}{|c|c|c|c|c|c|c|c|c|c|}
\hline \multirow[b]{2}{*}{ Orchard $^{b}$} & \multirow[b]{2}{*}{ Sample set ${ }^{c}$} & \multicolumn{4}{|c|}{ Group $1^{\mathrm{a}}$} & \multicolumn{4}{|c|}{ Group 2} \\
\hline & & No. leaves ${ }^{d}$ & Scab risk $^{\mathrm{e}}$ & Total $^{f}$ & Scab risk & No. leaves & Scab risk & Total & Scab risk \\
\hline \multirow[t]{6}{*}{ UVM 9} & 1 & 5 & Cont. & 21 & Low & 2 & Low & 26 & Low \\
\hline & 2 & 4 & Low & $\ldots$ & $\ldots$ & 3 & Low & $\ldots$ & $\ldots$ \\
\hline & 3 & 4 & Low & $\ldots$ & $\ldots$ & 3 & Low & $\ldots$ & $\ldots$ \\
\hline & 4 & 4 & Low & $\ldots$ & $\ldots$ & 8 & Cont. & $\ldots$ & $\ldots$ \\
\hline & 5 & 4 & Low & $\ldots$ & $\ldots$ & 3 & Low & $\ldots$ & $\ldots$ \\
\hline & 6 & 0 & Low & $\ldots$ & $\ldots$ & 7 & cont. & $\ldots$ & $\ldots$ \\
\hline \multirow[t]{6}{*}{ UVM 11} & 1 & 0 & Low & 2 & Low & 0 & Low & 2 & Low \\
\hline & 2 & 0 & Low & $\ldots$ & $\ldots$ & 1 & Low & $\ldots$ & $\ldots$ \\
\hline & 3 & 0 & Low & $\ldots$ & $\ldots$ & 0 & Low & $\ldots$ & $\ldots$ \\
\hline & 4 & 0 & Low & $\ldots$ & $\ldots$ & 0 & Low & $\ldots$ & $\ldots$ \\
\hline & 5 & 1 & Low & $\ldots$ & $\ldots$ & 0 & Low & $\ldots$ & $\ldots$ \\
\hline & 6 & 1 & Low & $\ldots$ & $\ldots$ & 1 & Low & $\ldots$ & $\ldots$ \\
\hline \multirow[t]{6}{*}{ Com. A-2 } & 1 & 33 & High & 249 & High & 69 & High & 370 & High \\
\hline & 2 & 54 & High & $\ldots$ & $\ldots$ & 89 & High & $\ldots$ & $\ldots$ \\
\hline & 3 & 43 & High & $\ldots$ & $\ldots$ & 46 & High & $\ldots$ & $\ldots$ \\
\hline & 4 & 41 & High & $\ldots$ & $\ldots$ & 55 & High & $\ldots$ & $\ldots$ \\
\hline & 5 & 44 & High & $\ldots$ & $\ldots$ & 56 & High & $\ldots$ & $\ldots$ \\
\hline & 6 & 34 & High & $\ldots$ & $\ldots$ & 55 & High & $\ldots$ & $\ldots$ \\
\hline \multirow[t]{6}{*}{ Com. A-3 } & 1 & 27 & High & 238 & High & 49 & High & 258 & High \\
\hline & 2 & 25 & High & $\ldots$ & $\ldots$ & 31 & High & $\ldots$ & $\ldots$ \\
\hline & 3 & 49 & High & $\ldots$ & $\ldots$ & 35 & High & $\ldots$ & $\ldots$ \\
\hline & 4 & 40 & High & $\ldots$ & $\ldots$ & 45 & High & $\ldots$ & $\ldots$ \\
\hline & 5 & 49 & High & $\ldots$ & $\ldots$ & 49 & High & $\ldots$ & $\ldots$ \\
\hline & 6 & 48 & High & $\ldots$ & $\ldots$ & 49 & High & $\ldots$ & $\ldots$ \\
\hline \multirow[t]{6}{*}{ Com. A-4 } & 1 & 171 & High & 773 & High & 133 & High & 985 & High \\
\hline & 2 & 101 & High & $\ldots$ & $\ldots$ & 197 & High & $\ldots$ & $\ldots$ \\
\hline & 3 & 166 & High & $\ldots$ & $\ldots$ & 191 & High & $\ldots$ & $\ldots$ \\
\hline & 4 & 166 & High & $\ldots$ & $\ldots$ & 173 & High & $\ldots$ & $\ldots$ \\
\hline & 5 & 68 & High & $\ldots$ & $\ldots$ & 122 & High & $\ldots$ & $\ldots$ \\
\hline & 6 & 101 & High & $\ldots$ & $\ldots$ & 169 & High & $\ldots$ & $\ldots$ \\
\hline \multirow[t]{6}{*}{ Com. B } & 1 & 26 & High & 139 & High & 16 & Cont. & 137 & High \\
\hline & 2 & 35 & High & $\ldots$ & $\ldots$ & 27 & High & $\ldots$ & $\ldots$ \\
\hline & 3 & 19 & Cont. & $\ldots$ & $\ldots$ & 23 & High & $\ldots$ & $\ldots$ \\
\hline & 4 & 19 & Cont. & $\ldots$ & $\ldots$ & 24 & High & $\ldots$ & $\ldots$ \\
\hline & 5 & 18 & Cont. & $\ldots$ & $\ldots$ & 24 & High & $\ldots$ & $\ldots$ \\
\hline & 6 & 22 & High & $\ldots$ & $\ldots$ & 23 & High & $\ldots$ & $\ldots$ \\
\hline \multirow[t]{6}{*}{ Com. C } & 1 & 51 & High & 265 & High & 51 & High & 248 & High \\
\hline & 2 & 45 & High & $\ldots$ & $\ldots$ & 48 & High & $\ldots$ & $\ldots$ \\
\hline & 3 & 37 & High & $\ldots$ & $\ldots$ & 40 & High & $\ldots$ & $\ldots$ \\
\hline & 4 & 34 & High & $\ldots$ & $\ldots$ & 31 & High & $\ldots$ & $\ldots$ \\
\hline & 5 & 47 & High & $\ldots$ & $\ldots$ & 34 & High & $\ldots$ & $\ldots$ \\
\hline & 6 & 51 & High & $\ldots$ & $\ldots$ & 44 & High & $\ldots$ & $\ldots$ \\
\hline \multirow[t]{6}{*}{ Com. D-1 } & 1 & 2 & Low & 17 & Low & 4 & Low & 21 & Low \\
\hline & 2 & 3 & Low & $\ldots$ & $\ldots$ & 3 & Low & $\ldots$ & $\ldots$ \\
\hline & 3 & 1 & Low & $\ldots$ & $\ldots$ & 3 & Low & $\ldots$ & $\ldots$ \\
\hline & 4 & 3 & Low & $\ldots$ & $\ldots$ & 4 & Low & $\ldots$ & $\ldots$ \\
\hline & 5 & 4 & Low & $\ldots$ & $\ldots$ & 4 & Low & $\ldots$ & $\ldots$ \\
\hline & 6 & 4 & Low & $\ldots$ & $\ldots$ & 3 & Low & $\ldots$ & $\ldots$ \\
\hline \multirow[t]{6}{*}{ Com. D-2 } & 1 & 2 & Low & 8 & Low & 0 & Low & 7 & Low \\
\hline & 2 & 1 & Low & $\ldots$ & $\ldots$ & 2 & Low & $\ldots$ & $\ldots$ \\
\hline & 3 & 2 & Low & $\ldots$ & $\ldots$ & 0 & Low & $\ldots$ & $\ldots$ \\
\hline & 4 & 3 & Low & $\ldots$ & $\ldots$ & 1 & Low & $\ldots$ & $\ldots$ \\
\hline & 5 & 0 & Low & $\ldots$ & $\ldots$ & 3 & Low & $\ldots$ & $\ldots$ \\
\hline & 6 & 0 & Low & $\ldots$ & $\ldots$ & 1 & Low & $\ldots$ & $\ldots$ \\
\hline
\end{tabular}

${ }^{\text {a }}$ All leaves on 20 extension shoots were evaluated for incidence of scab lesions. Sampling protocol for both the sequential sampling technique and the original, nonsequential procedure to determine scab risk required evaluating 10 shoots per tree. Group $1=$ data from 10 extension shoots per tree (every other shoot examined); Group $2=$ data from the remaining 10 extension shoots per tree.

${ }^{\mathrm{b}} \mathrm{UVM}=$ University of Vermont orchard and Com. = commercial orchard.

c Each sample set consisted of 10 trees.

d Number of scabbed leaves on 10 trees

e Scab risk indicates whether the number of scabbed leaves found on each set of 10 trees indicated a low- or high-risk level of scab when each sample set was considered the initial sample set in the sequential sampling technique (14). Cont. indicates that the level of scab was intermediate (i.e., between the threshold for a low- or high-risk determination) and that sampling must continue.

f Total number of scabbed leaves on 60 trees and scab risk; the original, nonsequential procedure to determine scab risk required the assessment of 60 trees (13). 
ments, the number of scabbed leaves was intermediate (i.e., above the threshold for low risk but below the threshold for high risk), indicating that sampling should continue. However, when the number of scabbed leaves from sets of trees were added together as they would be in the sequential sampling technique, a rating of low or high risk usually could be attained by adding only one or two additional sets of 10 trees. However, in commercial orchard B in 2001, 50 trees had to be sampled before a high-risk rating was obtained. In all incidences, the scab-risk rating was consistent with the rating obtained by evaluating 60 trees. For all other assessments (i.e., 160 of 180 assessments), evaluation of any of the 10 tree sets within an orchard provided a low-risk or high-risk rating consistent with the assessment of any of the other sets of 10 trees and was in agreement with the scab-risk rating pro- duced by the original, nonsequential procedure involving 60 trees.

Further analysis of the data using simulated, sequential sampling produced very consistent results within all orchards in both 2000 and 2001 (Tables 7 and 8). All 100 simulations within each orchard, using different tree and shoot combinations, produced the same result; either all simulations generated a low-risk rating or all generated a high-risk rating. However, not all simulations required only one set of 10 trees to determine scab risk. In some orchards, 20 to 30 trees were required in simulations and, in one orchard (i.e., commercial orchard B in 2001), 50 and 60 trees were required in two simulations, respectively, to produce a scab-risk rating (Table 8).

Delayed-spray experiments. In 2000, no significant difference in scab incidence was found in UVM orchards 9 and 11 be- tween delayed- and full-spray treatments on the cluster leaves $(P=0.0967$ and 0.2774 , respectively), extension shoot leaves $(P=0.6920$ and 0.8814 , respectively), or fruit $(P=0.1600$ and 0.7170 , respectively) according to $t$ tests (Table 9). Scab incidence on foliage and fruit was relatively low and commercially acceptable in contrast to incidence observed in nonfungicide-treated UVM orchards. For example, on nonfungicide-treated 'McIntosh' in UVM orchard 10, 69\% of the cluster leaves, $24 \%$ of the extension shoot leaves, and $100 \%$ of the fruit were scabbed. On 'Empire' trees in the nontreated section of UVM orchard 11 , there were $6 \%$ scabbed cluster leaves, $13 \%$ scabbed extension shoot leaves, and $28 \%$ scabbed fruit.

In 2001, significant differences between treatment means were detected in both UVM orchards 9 and 11 on cluster and extension shoot leaves (Table 9). In these

Table 6. Autumn scab-risk assessments, 2001

\begin{tabular}{|c|c|c|c|c|c|c|c|c|c|}
\hline \multirow[b]{2}{*}{ Orchard $^{b}$} & \multirow[b]{2}{*}{ Sample set ${ }^{c}$} & \multicolumn{4}{|c|}{ Group $1^{a}$} & \multicolumn{4}{|c|}{ Group 2} \\
\hline & & No. leaves $^{d}$ & Scab risk ${ }^{\mathrm{e}}$ & Total $^{f}$ & Scab risk ${ }^{f}$ & No. leaves & Scab risk & Total & Scab risk \\
\hline \multirow[t]{6}{*}{ UVM 9} & 1 & 81 & High & 374 & High & 85 & High & 431 & High \\
\hline & 2 & 61 & High & $\ldots$ & $\ldots$ & 72 & High & $\ldots$ & $\ldots$ \\
\hline & 3 & 57 & High & $\ldots$ & $\ldots$ & 73 & High & $\ldots$ & $\ldots$ \\
\hline & 4 & 55 & High & $\ldots$ & $\ldots$ & 76 & High & $\ldots$ & $\ldots$ \\
\hline & 5 & 54 & High & $\ldots$ & $\ldots$ & 59 & High & $\ldots$ & $\ldots$ \\
\hline & 6 & 66 & High & $\ldots$ & $\ldots$ & 66 & High & $\ldots$ & $\ldots$ \\
\hline \multirow{6}{*}{ UVM 11} & 1 & 52 & High & 252 & High & 52 & High & 254 & High \\
\hline & 2 & 42 & High & $\ldots$ & $\ldots$ & 38 & High & $\ldots$ & $\ldots$ \\
\hline & 3 & 34 & High & $\ldots$ & $\ldots$ & 38 & High & $\ldots$ & $\ldots$ \\
\hline & 4 & 37 & High & $\ldots$ & $\ldots$ & 31 & High & $\ldots$ & $\ldots$ \\
\hline & 5 & 35 & High & $\ldots$ & $\ldots$ & 29 & High & $\ldots$ & $\ldots$ \\
\hline & 6 & 52 & High & $\ldots$ & $\ldots$ & 66 & High & $\ldots$ & $\ldots$ \\
\hline \multirow[t]{6}{*}{ Com. B } & 1 & 16 & Cont. & 76 & High & 19 & Cont. & 69 & High \\
\hline & 2 & 15 & Cont. & $\ldots$ & $\ldots$ & 17 & Cont. & $\ldots$ & $\ldots$ \\
\hline & 3 & 10 & Cont. & $\ldots$ & $\ldots$ & 8 & Cont. & $\ldots$ & $\ldots$ \\
\hline & 4 & 11 & Cont. & $\ldots$ & $\ldots$ & 7 & Cont. & $\ldots$ & $\ldots$ \\
\hline & 5 & 7 & Cont. & $\ldots$ & $\ldots$ & 8 & Cont. & $\ldots$ & $\ldots$ \\
\hline & 6 & 17 & Cont. & $\ldots$ & $\ldots$ & 10 & Cont. & $\ldots$ & $\ldots$ \\
\hline \multirow[t]{6}{*}{ Com. E-1 } & 1 & 2 & Low & 15 & Low & 1 & Low & 4 & Low \\
\hline & 2 & 5 & Cont. & $\ldots$ & $\ldots$ & 2 & Low & $\ldots$ & $\ldots$ \\
\hline & 3 & 1 & Low & $\ldots$ & $\ldots$ & 0 & Low & $\ldots$ & $\ldots$ \\
\hline & 4 & 1 & Low & $\ldots$ & $\ldots$ & 0 & Low & $\ldots$ & $\ldots$ \\
\hline & 5 & 2 & Low & $\ldots$ & $\ldots$ & 0 & Low & $\ldots$ & $\ldots$ \\
\hline & 6 & 4 & Low & $\ldots$ & $\ldots$ & 1 & Low & $\ldots$ & $\ldots$ \\
\hline \multirow[t]{6}{*}{ Com. E-2 } & 1 & 0 & Low & 1 & Low & 2 & Low & 3 & Low \\
\hline & 2 & 1 & Low & $\ldots$ & $\ldots$ & 0 & Low & $\ldots$ & $\ldots$ \\
\hline & 3 & 0 & Low & $\ldots$ & $\ldots$ & 0 & Low & $\ldots$ & $\ldots$ \\
\hline & 4 & 0 & Low & $\ldots$ & $\ldots$ & 0 & Low & $\ldots$ & $\ldots$ \\
\hline & 5 & 0 & Low & $\ldots$ & $\ldots$ & 0 & Low & $\ldots$ & $\ldots$ \\
\hline & 6 & 0 & Low & $\ldots$ & $\ldots$ & 1 & Low & $\ldots$ & $\ldots$ \\
\hline \multirow[t]{6}{*}{ Com. F } & 1 & 59 & High & 460 & High & 60 & High & 445 & High \\
\hline & 2 & 97 & High & $\ldots$ & $\ldots$ & 74 & High & $\ldots$ & $\ldots$ \\
\hline & 3 & 67 & High & $\ldots$ & $\ldots$ & 67 & High & $\ldots$ & $\ldots$ \\
\hline & 4 & 126 & High & $\ldots$ & $\ldots$ & 128 & High & $\ldots$ & $\ldots$ \\
\hline & 5 & 46 & High & $\ldots$ & $\ldots$ & 58 & High & $\ldots$ & $\ldots$ \\
\hline & 6 & 65 & High & $\ldots$ & $\ldots$ & 58 & High & $\ldots$ & $\ldots$ \\
\hline
\end{tabular}

\footnotetext{
${ }^{a}$ All leaves on 20 extension shoots were evaluated for incidence of scab lesions. Sampling protocol for both the sequential sampling technique and the original, nonsequential procedure to determine scab risk required evaluating 10 shoots per tree. Group $1=$ data from 10 extension shoots per tree (every other shoot examined); group $2=$ data from the remaining 10 extension shoots per tree.

${ }^{\mathrm{b}} \mathrm{UVM}=$ University of Vermont orchards and Com. = commercial orchards.

c Each sample set consisted of 10 trees.

d Number of scabbed leaves on 10 trees.

e Scab risk indicates whether the number of scabbed leaves found on each set of 10 trees indicated a low- or high-risk level of scab when each sample set was considered the initial sample set in the sequential sampling technique (14). Cont. indicates the level of scab was intermediate (i.e., between the threshold for a low- or high-risk determination) and that sampling must continue.

f Total number of scabbed leaves on 60 trees and scab risk; the original, nonsequential procedure to determine scab risk required the assessment of 60 trees (13).
} 
orchards, foliar scab incidence was higher in 2001 compared with 2000 but still was lower than that observed on nonfungicidetreated 'McIntosh' trees in UVM orchard 10 , where $68 \%$ of the cluster leaves and $40 \%$ of the terminal leaves were scabbed. On nonfungicide-treated 'Empire' trees in UVM orchard 11, $13 \%$ of the cluster leaves and $17 \%$ of the terminal leaves were scabbed.

On the fruit, there was no significant difference between treatment means in either orchard in 2001. In orchard 9, scab incidence on fruit was below the $1 \%$ commercial threshold; however, fruit scab was above threshold in orchard 11 (Table 9). On nonfungicide-treated trees, fruit scab incidence was $91 \%$ on 'McIntosh' and $45 \%$ on 'Empire' in UVM orchards 10 and 11 , respectively.

\section{DISCUSSION}

Sequential sampling experiments. The sequential sampling technique proposed by MacHardy et al. (14) produced consistent results when repeated within an orchard.
The technique also produced the same scab-risk rating as the original, nonsequential procedure that involved assessing 60 trees although, in some orchards, more than the minimum of 10 trees had to be assessed to obtain a scab-risk rating.

It should be noted that there are only two possible outcomes to the sequential sampling technique, a low- or high-risk rating, indicating the risk of developing unacceptable levels of fruit scab the following year if the delayed-spray strategy were to be implemented. An orchard with an intermediate level of foliar scab (e.g., 51 to 100 scabbed leaves on 600 shoots sampled from 60 trees) would be considered a high-risk orchard unless sanitation practices were to be employed (14). The orchards in this study originally were selected to represent the range of well-managed orchards that would potentially have low to intermediate levels of foliar scab and, thus, provide realistic environments in which to evaluate the sampling technique. Scab levels during 2000 and 2001 in these orchards ranged from very low to high; only commercial orchard B had levels of foliar scab that were within or slightly above the intermediate level based on the 60-tree assessment (i.e., an average of 138 and 72 scabbed leaves in 2000 and 2001, respectively) (Tables 5 and 6). Therefore, in field evaluations and simulations in this orchard in both years of the study, it potentially required a number of sets of 10 trees to determine the risk rating (Tables 5 to 8 ). In commercial orchard A-3, where the average total number of scabbed leaves on 60 trees was 248 , two sets of 10 trees were required to determine a high-risk rating in 3 of 100 simulations (Table 7). In all the other orchards that had higher average levels of foliar scab, a single set of 10 trees produced a high-risk rating in either the field evaluations or in the simulations (Tables 5 to 8 ).

In orchards where the average total number of scabbed leaves on 60 trees ranged from 7 to 30 , the assessment of certain sets of trees indicated potentially intermediate levels of scab. This occurred in commercial orchard A-1 in 1999 (field

Table 7. Comparison of autumn scab risk ratings as determined by the sequential sampling technique, the original nonsequential procedure, and simulation, 2000

\begin{tabular}{|c|c|c|c|c|c|c|c|c|c|c|c|c|c|c|c|c|}
\hline \multirow[b]{3}{*}{ Orchard } & \multicolumn{4}{|c|}{ Scab risk level } & \multirow{2}{*}{\multicolumn{6}{|c|}{$\begin{array}{l}\text { Simulations related to sets of trees } \\
\text { required for low risk generation }\end{array}$}} & \multirow{2}{*}{\multicolumn{6}{|c|}{$\begin{array}{l}\text { Simulations related to sets of trees } \\
\text { required for high risk generation }\end{array}$}} \\
\hline & \multirow[b]{2}{*}{ Sequential $^{\mathrm{a}}$} & \multirow[b]{2}{*}{ Nonsequential $^{\text {b }}$} & \multicolumn{2}{|c|}{ Simulated sequential $^{\mathrm{c}}$} & & & & & & & & & & & & \\
\hline & & & Low & High & 1 & 2 & 3 & 4 & 5 & 6 & 1 & 2 & 3 & 4 & 5 & 6 \\
\hline UVM 9 & Low & Low & 100 & 0 & 64 & 31 & 5 & 0 & 0 & 0 & 0 & 0 & 0 & 0 & 0 & 0 \\
\hline UVM 11 & Low & Low & 100 & 0 & 100 & 0 & 0 & 0 & 0 & 0 & 0 & 0 & 0 & 0 & 0 & 0 \\
\hline Commercial A-2 & High & High & 0 & 100 & 0 & 0 & 0 & 0 & 0 & 0 & 100 & 0 & 0 & 0 & 0 & 0 \\
\hline Connercial A-3 & High & High & 0 & 100 & 0 & 0 & 0 & 0 & 0 & 0 & 97 & 3 & 0 & 0 & 0 & 0 \\
\hline Commercial A-4 & High & High & 0 & 100 & 0 & 0 & 0 & 0 & 0 & 0 & 100 & 0 & 0 & 0 & 0 & 0 \\
\hline Commercial B & High & High & 0 & 100 & 0 & 0 & 0 & 0 & 0 & 0 & 73 & 27 & 0 & 0 & 0 & 0 \\
\hline Commercial C & High & High & 0 & 100 & 0 & 0 & 0 & 0 & 0 & 0 & 100 & 0 & 0 & 0 & 0 & 0 \\
\hline Commercial D-1 & Low & Low & 100 & 0 & 76 & 23 & 1 & 0 & 0 & 0 & 0 & 0 & 0 & 0 & 0 & 0 \\
\hline Commercial D-2 & Low & Low & 100 & 0 & 97 & 3 & 0 & 0 & 0 & 0 & 0 & 0 & 0 & 0 & 0 & 0 \\
\hline
\end{tabular}

a Sampling protocol followed MacHardy et al. (14).

b Sampling protocol followed MacHardy (13).

${ }^{\mathrm{c}}$ Data are the number of simulations out of a total of 100 that generated a low or high scab risk rating using a computer simulation program (18).

${ }^{d}$ Data represent the number of simulations related to the number of sets of trees required to generate the level of scab risk. The number of sets of trees required was based on the number of scabbed leaves observed for each set and the thresholds to stop sampling or to continue for each successive set (14). For example, in University of Vermont orchard 9, 64 simulations required only the initial set of 10 trees to determine the scab risk level of the orchard; 31 simulations required an additional set of 10 trees to determine the scab risk level; and 5 simulations required 3 sets of trees (i.e., 30 trees) to come to a determination of scab risk based on thresholds proposed by MacHardy et al. (14).

Table 8. Comparison of autumn scab risk ratings as determined by the sequential sampling technique, the original nonsequential procedure, and simulation, 2001

\begin{tabular}{|c|c|c|c|c|c|c|c|c|c|c|c|c|c|c|c|c|}
\hline \multirow[b]{3}{*}{ Orchard } & \multicolumn{4}{|c|}{ Scab risk level } & \multirow{2}{*}{\multicolumn{6}{|c|}{$\begin{array}{l}\text { Simulations related to sets of trees } \\
\text { required for low risk generation }\end{array}$}} & \multirow{2}{*}{\multicolumn{6}{|c|}{$\begin{array}{l}\text { Simulations related to sets of trees } \\
\text { required for high risk generationd }\end{array}$}} \\
\hline & \multirow[b]{2}{*}{ Sequential $^{\mathrm{a}}$} & \multirow[b]{2}{*}{ Nonsequential $^{\text {b }}$} & \multicolumn{2}{|c|}{ Simulated sequential $^{\mathrm{c}}$} & & & & & & & & & & & & \\
\hline & & & Low & High & 1 & 2 & 3 & 4 & 5 & 6 & 1 & 2 & 3 & 4 & 5 & 6 \\
\hline UVM 9 & High & High & 0 & 100 & 0 & 0 & 0 & 0 & 0 & 0 & 100 & 0 & 0 & 0 & 0 & 0 \\
\hline UVM 11 & High & High & 0 & 100 & 0 & 0 & 0 & 0 & 0 & 0 & 100 & 0 & 0 & 0 & 0 & 0 \\
\hline Commercial B & High & High & 0 & 100 & 0 & 0 & 0 & 0 & 0 & 0 & 2 & 40 & 39 & 17 & 1 & 1 \\
\hline Connercial E-1 & Low & Low & 100 & 0 & 99 & 1 & 0 & 0 & 0 & 0 & 0 & 0 & 0 & 0 & 0 & 0 \\
\hline Commercial E-2 & Low & Low & 100 & 0 & 100 & 0 & 0 & 0 & 0 & 0 & 0 & 0 & 0 & 0 & 0 & 0 \\
\hline Commercial F & High & High & 0 & 100 & 0 & 0 & 0 & 0 & 0 & 0 & 100 & 0 & 0 & 0 & 0 & 0 \\
\hline
\end{tabular}

a Sampling protocol followed MacHardy et al. (14)

b Sampling protocol followed MacHardy (13).

${ }^{c}$ Data are the number of simulations out of a total of 100 that generated a low or high scab risk rating using a computer simulation program (18).

${ }^{d}$ Data represent the number of simulations related to the number of sets of trees required to generate the level of scab risk. The number of sets of trees required was based on the number of scabbed leaves observed for each set and the thresholds to stop sampling or to continue for each successive set (14). For example, in commercial orchard E-1, 99 simulations required only the initial set of 10 trees to determine the scab-risk level of the orchard, and 1 simulation required an additional set of 10 trees to come to a determination of scab risk based on thresholds proposed by MacHardy et al. (14). 
evaluation), UVM orchard 9 (field evaluation and simulation), commercial orchard D-1 (simulation), and commercial orchard D-2 (simulation) in 2000; and commercial orchard E-1 in 2001 (field evaluation and simulation) (Tables 5 to 8). The scab level in these orchards was below the high-risk rating threshold but apparently exceeded the level of scab that would immediately provide a low-risk rating when specific trees or shoots were selected, which may be the situation in many well-managed, commercial orchards throughout the region.

The sequential sampling technique is an important improvement over the original procedure because it potentially would save apple growers, or their consultants, considerable time in assessing their orchards, thus facilitating adoption. Adoption of this technique would provide growers with valuable information that would allow them to decide the necessity of early spring fungicide sprays. In low-risk orchards, the initial fungicide application can be delayed, reducing the overall fungicide dose in an orchard and allowing for better integration of fungicide and insecticide applications during the prebloom period. Reduction in applications of some fungicides also may translate into reduced pressure for the development of fungicide resistance. Thus, adoption of the sequential sampling technique potentially would result in economic and environmental benefits.

Delayed-spray experiments. Although studies have shown that delaying the first spray in orchards having a low potential ascospore dose does not result in unacceptable levels of fruit scab at harvest $(13,16)$, these studies did not use the sequential sampling technique to determine the scab risk level of the orchards. One of the objectives of this research was to determine if using the delayed-spray strategy in orchards identified as low risk by the sequential sampling technique would result in commercially unacceptable levels of scabbed fruit at harvest (i.e., $>1 \%$ ). In 2000 , the delayed-spray replicates had been exposed to infection from 21 to 24 April 2000, when approximately $6 \%$ of the total ascospore dose for the season poten- tially was released, and perhaps partially exposed during the beginning of the 8 to 12 May 2000 primary infection period, when potentially $29 \%$ of the total ascospore dose was released (Table 2). Yet foliar and fruit scab was not significantly different from the full-spray replicates in both orchards and the delayed-spray strategy clearly resulted in commercially acceptable fruit at harvest in both orchards with three fewer fungicide applications (Table 9). The 2000 growing season was considered a challenging year for apple scab management (i.e., a good test year) because of frequent rains during the remainder of the growing season. Because the 2000 autumn assessment of foliar scab indicated low risk, the orchards again were candidates for a delayed-spray strategy in 2001 (Table 5). There were no significant differences in foliar scab on either cluster leaves or extension shoots between trees in the delayed-spray and full-spray treatments in both orchards in 2000 and the autumn assessments involving 60 trees in both orchards produced low-risk ratings; therefore, treatment replicates were not rerandomized in 2001 and involved the same trees in order to more closely represent a commercial orchard situation, where the same trees might be involved in a delayedspray program over multiple years.

In 2001, no primary infection periods occurred before the bloom stage of bud development, which is highly unusual in Vermont; therefore, the first fungicide spray was applied later than the sequential sampling technique protocol recommended (Table 2) in order for the delayed-spray replicates to be exposed to at least one primary infection period (i.e., 12 to 13 May 2001). In a commercial setting, the first fungicide would have been applied at the pink stage. MacHardy et al. (16) found it possible to stretch the delayed-spray period until bloom without subsequent unacceptable levels of scab. Unfortunately, it was estimated that almost $50 \%$ of the total ascospore dose of the season was released during this primary infection period (18) and, subsequently, it was considered the most significant primary infection period of the season and the major factor in the increase in foliar scab levels in both orchards in 2001. In both orchards, there was a significantly higher incidence of foliar scab on delayed-spray replicates compared with full-spray replicates. However, UVM orchard 9 did not have significantly different levels of fruit scab at harvest between treatment replicates and the level was commercially acceptable. Again, there was a savings of three fungicide applications between delayed- and full-spray treatments in 2001 in UVM orchard 9. In UVM orchard 11, there also was a savings of three fungicide applications between delayed- and full-spray replicates. The level of fruit scab was not significantly different between treatments, but the level was commercially unacceptable. Although the level of fruit scab was the same between treatments, 10 of the 11 replicates of the delayed-spray treatment had scab, whereas fruit scab was not observed on 5 replicates of the full-spray treatment, indicating that incomplete spray coverage or uneven distribution of overwintering inoculum within the orchard may have been factors in the level of fruit scab observed.

A negative consequence of the foliar scab levels in UVM orchards 9 and 11 in 2001 was that the autumn assessment of scab risk determined that both orchards were at high risk for the next spring and, thus, fungicide sprays could not be delayed in 2002 in either orchard unless a thorough autumn sanitation treatment (i.e., urea and leaf shredding) was applied when all the leaves had fallen that would reduce the ascosporic inoculum by $90 \%$ (21). Such a sanitation program would place the orchards again in the low-risk category and they would be candidates for the delayedspray strategy the following spring. It is interesting to speculate whether the overall foliar scab level in these orchards would have been lower and within the low-risk category if the recommended action threshold had been followed and spraying had commenced at the pink bud stage on trees in the delayed-spray treatment.

In conclusion, this research showed that the sequential sampling technique proposed by MacHardy et al. (14) provides scab-risk orchard ratings consistent with the original, nonsequential procedure (13), at potentially a significant time savings.

Table 9. Proportion of leaves and fruit with scab by location, year, and treatment

\begin{tabular}{|c|c|c|c|c|c|c|c|c|c|c|c|c|c|}
\hline \multirow{2}{*}{$\begin{array}{l}\text { UVM } \\
\text { Orchard }\end{array}$} & \multirow[b]{2}{*}{ Year } & \multicolumn{4}{|c|}{ Cluster leaf scab ${ }^{a}$} & \multicolumn{4}{|c|}{ Extension shoot leaf scab ${ }^{a}$} & \multicolumn{4}{|c|}{ Fruit scab $^{\mathbf{b}}$} \\
\hline & & Date & Delayed & Full & $P$ value & Date & Delayed & Full & $P$ value & Date & Delayed & Full & $P$ value \\
\hline Orchard 9 & 2000 & 19-20 June & 0.008 & 0.004 & 0.0967 & 22-24 June & 0.011 & 0.008 & 0.6920 & $21 \mathrm{Aug}$ & 0.008 & 0.003 & 0.1600 \\
\hline Orchard 11 & 2000 & 20-22 June & 0.004 & 0.002 & 0.2774 & 24-26 June & 0.002 & 0.003 & 0.8814 & 23-24 Aug & 0.004 & 0.003 & 0.7170 \\
\hline Orchard 9 & 2001 & 5-6 June & 0.040 & $0.006 *$ & $<0.0001$ & $\begin{array}{l}7 \text { June } \\
1 \text { Aug }\end{array}$ & $\begin{array}{l}0.052 \\
0.064\end{array}$ & $\begin{array}{l}0.023^{*} \\
0.020^{*}\end{array}$ & $\begin{array}{l}<0.0001 \\
<0.0001\end{array}$ & 21 Aug & 0.008 & 0.003 & 0.1090 \\
\hline Orchard 11 & 2001 & 5 June & 0.081 & $0.002 *$ & $<0.0001$ & $\begin{array}{l}\text { 6-7 June } \\
\text { 1-2 Aug }\end{array}$ & $\begin{array}{l}0.044 \\
0.064\end{array}$ & $\begin{array}{l}0.017 * \\
0.025 *\end{array}$ & $\begin{array}{l}<0.0001 \\
<0.0001\end{array}$ & $21 \mathrm{Aug}$ & 0.023 & 0.023 & 0.3989 \\
\hline
\end{tabular}

a Data represent mean proportion of scab incidence on all leaves on 10 clusters and 10 extension shoots per tree on each of 12 delayed-spray and 11 fullspray two-tree replicates in University of Vermont (UVM) orchard 9 and on each of 11 delayed-spray and 11 full-spray two-tree replicates in UVM orchard $11 ;$ * indicates significant difference.

${ }^{\mathrm{b}}$ Data represent mean proportion of scab incidence on 50 fruit per tree on each of 12 delayed-spray and 11 full-spray two-tree replicates in UVM orchard 9 and on each of 11 delayed- and 11 full-spray two-tree replicates in UVM orchard 11; * indicates significant difference. 
This research also demonstrated that following the delayed-spray strategy in lowrisk orchards did not result in significant differences in fruit scab at harvest compared with spraying from the green-tip bud stage. It is hoped that this study will address the reservations that apple growers may have in implementing the sequential sampling technique and the delayed-spray strategy and facilitate adoption.

\section{ACKNOWLEDGMENTS}

We thank W. MacHardy for reviewing the manuscript, G. Koehler and T. L. Bradshaw for their technical assistance, and S. L. Kingsley-Richards for her assistance in the preparation of the manuscript.

\section{LITERATURE CITED}

1. Berkett, L. P., ed. 2000. Apple scab biology and epidemiology. Pages 7-11 in: 2000-2001 New England Apple Pest Management Guide. G. Koehler, ed. Cooperative Extension Service, Universities of Connecticut, Maine, Massachusetts, New Hampshire, Rhode Island, and Vermont.

2. Berkett, L. P., MacHardy, W. E., Sutton, D. K., Neff, G., and Bradshaw, T. 1997. "Whole farm" apple scab IPM project. Proc. 103th Annu. Meet. Mass. Fruit Grow. Assoc. Inc. 103:132-137.

3. Berkett, L. P., and Wolfgang, S. 1990. Introduction. Pages 1-2 in: Management Guide for Low Input Apple Production. USDA Northeast Low Input Sustainable Agriculture Apple Production Project, Cornell University, Rodale Research Center, Rutgers University, University of Massachu- setts, and University of Vermont.

4. Burchill, R. T., Hutton, K. E., Crosse, J. E., and Garrett, C. M. E. 1965. Inhibition of the perfect stage of Venturia inaequalis (Cke.) Wint., by urea. Nature 205:520-521.

5. Chapman, P. J., and Catlin, G. A. 1976. Growth stages in fruit trees. N. Y. Food Life Sci. Bull. 58. N. Y. Agric. Exp. Stn. Geneva, NY.

6. Gadoury, D. M., and MacHardy, W. E. 1982. A model to estimate the maturity of ascospores of Venturia inaequalis. Phytopathology 72:901-904.

7. Gadoury, D. M., and MacHardy, W. E. 1986. Forecasting ascospore dose of Venturia inaequalis in commercial apple orchards. Phytopathology 76:112-118.

8. Gadoury, D. M., MacHardy, W. E., and Rosenberger, D. A. 1989. Integration of pesticide application schedules for disease and insect control in apple orchards in the northeastern United States. Plant Dis. 73:98-105.

9. Gadoury, D. M., Seem, R. C., and Stensvand, A. 1995. New developments in forecasting the risk of apple scab. N. Y. Fruit Q. 2:5-8.

10. Koehler, G. W., ed. 1998. 1998-1999 New England Apple Pest Management Guide. Cooperative Extension Service, Universities of Connecticut, Maine, Massachusetts, New Hampshire, Rhode Island, and Vermont.

11. MacHardy, W. E. 1994. A "PAD" action threshold: the key to integrating practices for managing apple scab. Pages 75-82 in: Integrated Control of Pome Fruit Diseases. Denis J. Butt, ed. Norw. J. Agric. Sci. Suppl. No. 17.

12. MacHardy, W. E. 1996. Modes of overwintering. Pages 190-195 in: Apple Scab Biology, Epidemiology and Management. American Phytopathological Society Press, St. Paul, MN.

13. MacHardy, W. E. 1998. Action thresholds for managing apple scab with fungicides and sanitation. Acta Hortic. 52:123-131.

14. MacHardy, W. E., Berkett, L. P., Neefus, C. D., Gotlieb, A. R., and Sutton, D. K. 1999. An autumn foliar scab sequential sampling technique to predict the level of "scab-risk" next spring. (Abstr.) Phytopathology 89:S47.

15. MacHardy, W. E., and Gadoury, D. M. 1989. A revision of Mill's criteria for predicting apple scab infection periods. Phytopathology 79:304-310.

16. MacHardy, W. E., Gadoury, D. M., and Rosenberger, D. A. 1993. Delaying the onset of fungicide programs for control of apple scab in orchards with low potential ascospore dose of Venturia inaequalis. Plant Dis. 77:372-375.

17. MacHardy, W. E., and Jeger, M. J. 1983. Integrating control measures for the management of primary apple scab, Venturia inaequalis (Cke.) Wint. Prot. Ecol. 5:103-125.

18. Reardon, J. E. 2002. Field validation of a new sequential sampling technique for determining 'risk' of apple scab in Vermont apple orchards. M.S. thesis, University of Vermont, Burlington.

19. Ross, R. G., and Burchill, R. T. 1968. Experiments using sterilized apple-leaf discs to study the mode of action of urea in suppressing the perithecia of Venturia inaequalis (Cke.) Wint. Ann. Appl. Biol. 62:289-296.

20. Stensvand, A., Gadoury, D. M., Amundsen, T. Semb, L., and Seem, R. C. 1997. Ascospore release and infection of apple leaves by conidia and ascospores of Venturia inaequalis at low temperatures. Phytopathology 87:1046-1053.

21. Sutton, D. K., MacHardy, W. E., and Lord, W. G. 2000. Effects of shredding or treating apple leaf litter with urea on ascospore dose of Venturia inaequalis and disease buildup. Plant Dis. 84:1319-1326. 